\title{
Supraventricular Tachyarrhythmia ECG Assessment
}

National Cancer Institute

\section{Source}

National Cancer Institute. Supraventricular Tachyarrhythmia ECG Assessment. NCI

Thesaurus. Code C111321.

An electrocardiographic assessment of the abnormally fast cardiac rhythms originating above the ventricles. 